\title{
A case study on a fire-induced collapse accident of a reinforced concrete frame-supported masonry structure
}

$\mathrm{Yi} \mathrm{Li}^{\mathrm{a}}$, Xinzheng Lu ${ }^{\mathrm{b} *}$, Hong Guan ${ }^{\mathrm{c}}$, Mingjian Ying ${ }^{\mathrm{b}}$, Weiming Yan ${ }^{\mathrm{a}}$ a. Key Laboratory of Urban Security and Disaster Engineering of Ministry of Education, Beijing

Collaborative Innovation Center for Metropolitan Transportation, Beijing University of Technology, Beijing 100124, China

b. Key Laboratory of Civil Engineering Safety and Durability of Ministry of Education,

Department of Civil Engineering, Tsinghua University, Beijing 100084, China

c. Griffith School of Engineering, Griffith University Gold Coast Campus, Queensland 4222, Australia

*Corresponding Author: Xinzheng Lu, Email: Luxz@tsinghua.edu.cn Tel:+(86)10 62795364, Fax:+(86)10 62795364

Abstract: In 2003, an 8-storey reinforced concrete (RC) frame-supported masonry structure, located in Hengyang City, China, underwent a severe fire-induced collapse accident. Information on the structure and the fire scenario is presented. It includes the design data, the site observation record of the fire incident, and the laboratory material test results. Preliminary investigation reveals that about $45.9 \%$ of the bottom storey of the RC frame was predicted to have experienced temperatures in excess of $800^{\circ} \mathrm{C}$, and its central area was predicted to have reached almost $1300^{\circ} \mathrm{C}$. Such a severe fire load, of fairly high temperature and covering a large area, is thought to be the primary cause of the progressive collapse of the entire building structure. To better understand the collapse mechanism, this study presents a coupled thermo-mechanical numerical simulation of the building collapse. The simulation results confirm that the actual collapse area is well reproduced by the proposed numerical model. The simulation further demonstrates that the initial damage happened to two interior columns exposed to an extreme temperature of $1300^{\circ} \mathrm{C}$. Such damage was also attributable to the large gravity load they carried, and the complicated nature of the local structural arrangements. Their adjacent structural members were subsequently damaged, because they were also weakened by the severe fire, and they were over-loaded by the redistributed load originally resisted by the two formerly damaged columns. Failure of the two interior columns and their adjacent area eventually triggered a progressive collapse of the remaining structure. Further, the effect of some critical factors on the 
collapse mechanism is discussed. On the basis of this numerical case study, practical design considerations on the key structural components, the fire compartments, and the structural robustness are given for the prevention of the fire-induced progressive collapse of RC frame structures.

Keywords: Frame-supported masonry structure; fire-induced collapse; site investigation; numerical simulation

\section{Introduction}

In 2003, the Hengzhou Building, an 8-storey RC frame-supported masonry structure, located in the Hengyang City of China, suffered a severe fire. Following an approximately three hour fire, the building collapsed. It claimed the lives of 20 firefighters, with 16 injuries. A fire-induced collapse is a complicated mechanical behavior of an overall structural system under a critical limit state. Such a behavior covers material degradations (at high temperature), large deformations of structural members, and load redistributions in structural systems. An in-depth investigation into the real-world mechanism of a fire-induced collapse incident of a building structure or structures would be very helpful for understanding their overall mechanical behavior in fire. However, such a scientific investigation is rarely reported. Thus, this study aims to present a case study on the Hengzhou Building, which will provide useful engineering lessons for improving fire-induced collapse prevention design considerations.

Existing studies have demonstrated that the behavior of structural elements under fire can be different from that observed during the standard furnace tests ${ }^{[1]}$. In a real scenario, when a building is exposed to a fire, additional internal forces are produced because the fire-induced thermal expansions of the structural components are restrained by the surrounding components. However, this important effect is often neglected in the standard furnace tests on structural components, where constant loads 
are normally applied ${ }^{[2]}$. During the late 1990s, a series of full-scale fire tests were successfully conducted at the Large Building Test Facility of the Building Research Establishment (BRE) at Cardington. These tests studied the fire resistance of entire steel and concrete structures ${ }^{[3-5]}$. Despite such research efforts, similar large-scale tests were not widely used in the fire safety design and the analysis of the entire structural systems due to extremely high laboratory and labor costs. In contrast, Mostafaei ${ }^{[6]}$ adopted a hybrid experimental method to study the fire resistance of a single column in a structural system. Similar work was conducted at the CERIB of France, which has testing facilities with active loading systems ${ }^{[7]}$. However, the capacity of the fire furnaces limited the size and number of the structural members to be tested ${ }^{[8]}$.

A numerical simulation, on the other hand, offers a low-cost and effective tool to evaluate the fire performance of an overall structure system. Many researchers have developed numerical models to simulate the behavior of steel and concrete structures under fire, such as SAFIR ${ }^{[9]}$ and VULCAN ${ }^{[10]}$. In addition, commercial finite element (FE) codes, such as ABAQUS, have been adopted by others ${ }^{[11-13]}$ to perform the analysis of structures at elevated temperatures. Furthermore, research efforts to promote more feasible and more robust numerical methods are still in high demand and these methods must be carefully validated with representative experimental results.

In addition to the experimental and analytical methods, accident investigation is also an important methodology for studying the fire resistance of an overall structural system. Unlike the idealized structural models used in experimental and analytical studies, real-world structures are free from any simplifications. The critical issues that may be neglected in existing engineering designs and analyses can be discovered through accident investigations of real structures under fire accidents.

For example, in studying the collapse of the World Trade Center (WTC) towers in 
New York, Usmani et al. ${ }^{[14]}$ discovered that the building floors were softened by fire and, in turn, the lateral restraint of the peripheral truss columns were weakened. These outcomes resulted in a large, horizontal tensile force from the floor on the peripheral truss columns, and eventually accelerated the failure of the columns. These aspects were, however, not considered in the original design of the WTC. Quintiere et al. ${ }^{[15]}$ suggested that the insulation thickness on the truss rods was insufficient, thereby causing the over-heating of the steel. In turn this led to the weakening and collapsing of the trusses. NIST ${ }^{[16-19]}$ also conducted a comprehensive investigation of this accident and provided many important conclusions which promoted on-going efforts in fire safety research.

Other studies have address buildings under severe fire, for example, the Windsor Tower of Madrid. The fire development of this accident was studied to replicate the growth and spread of the fire and identify the impact of the fire on structural behavior $^{[20]}$. The lack of fire protection for the steelwork was believed to be the major reason for the partial collapse of the building ${ }^{[21]}$. In addition, similar work was also been conducted to provide engineering lessons from fire-induced collapse accidents of some other real structures and commercial building projects ${ }^{[22]}$.

To implement the direct assessment of the performance of the overall structural systems under fire, comprehensive fire incident reports and investigations (including details such as the design data, the structural damage, and the fire development scenario) can provide very valuable and representative benchmark models for fire science. These models can also be used to conduct in-depth studies of the structures under fire through which new methodologies for fire analysis can be validated, and potential fire-induced problems of typical structures can be further explored. However, detailed fire incident reports on other fire-induced collapse accidents ${ }^{[23]}$, other than those for the WTC and the Windsor Tower fires, are still very limited in the literature.

In the current study, the complete structural and fire data of the Hengzhou Building, 
including its design information, the site observation records for the fire disaster, and the laboratory material test results, were collected and summarized to provide a benchmark case for further fire studies. To gain an in-depth understanding of the collapse mechanisms, the entire collapse process of the structure was simulated using a combination of fiber beam elements, multi-layer shell elements, component failure criteria, and elemental deactivation technology. The primary cause of the fire-induced structural collapse is discussed, and suggestions are given to the progressive collapse prevention design considerations against fire hazards.

\section{Structural and material related data of the building}

Located in Hengyang, China, the 1998 constructed Hengzhou Building was an 8-storey, 25.8-m tall RC frame-supported masonry structure. The planar layout of the building is shown in Figure 1. Its ground floor was $4.8 \mathrm{~m}$ high and it was originally designed for commercial use. The first through to the seventh floors of the building were $3 \mathrm{~m}$ in height, and these stories were designed for the residents. The design loads consisted of $5 \mathrm{kN} / \mathrm{m}^{2}$ of dead load and $2 \mathrm{kN} / \mathrm{m}^{2}$ of live load.

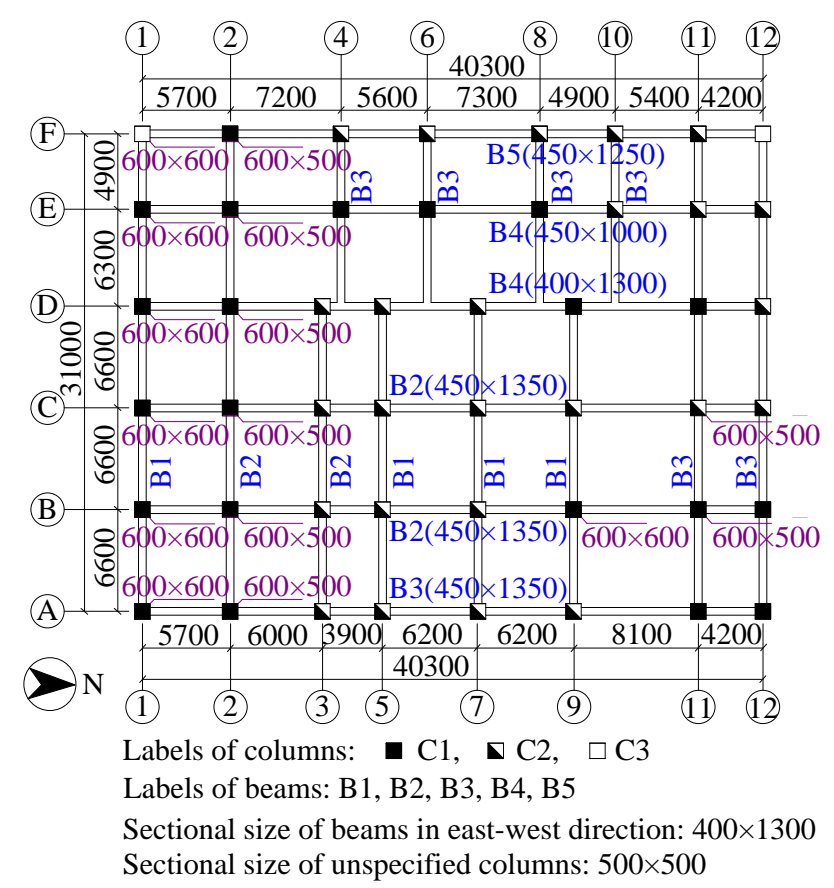

Figure 1 Structural arrangement of the ground floor frame and member sizes (unit: mm) 


\subsection{RC frame on the ground floor}

The structural layout of the ground floor frame, as well as the dimensions and designations of the structural components, is detailed in Figure 1. The reinforcement details of the frame are given in Table 1 . The floor slabs were precast and were separated from the main frame. The concrete strength was C30 for the columns and beams, with a design compressive strength, $f_{\mathrm{c}}$, of $20.1 \mathrm{MPa}$. Through the on-site rebound hammer test and the laboratory compressive test of the drilled cores ${ }^{[24,25]}$, the actual compressive strength of the concrete samples that were free from fire damage varied from 28.0 MPa to $41.7 \mathrm{MPa}$, with an average strength of $36.2 \mathrm{MPa}$, and a standard deviation of 4.1 MPa. Hot-rolled ribbed steel bars were used for longitudinal reinforcement, with a design yield strength, $f_{\mathrm{y}}$, and an ultimate tensile strength, $f_{\mathrm{t}}$, of $335 \mathrm{MPa}$ and $510 \mathrm{MPa}$, respectively. The laboratory tensile test demonstrated that the average yield and the tensile strengths of reinforcement were $398 \mathrm{MPa}$ and $574 \mathrm{MPa}$, respectively. These results meet the design specifications ${ }^{[26,27]}$. Plain bars were used for the stirrups, with a design yield strength, $f_{\mathrm{y}}$, and ultimate tensile strength, $f_{\mathrm{t}}$, of 235 $\mathrm{MPa}$ and $375 \mathrm{MPa}$, respectively. The laboratory tensile test also confirmed that the average yield strength of the stirrups of 321 MPa satisfied the design value. However, the actual tensile strength, $f_{\mathrm{t}}$, of one of the three stirrups was approximately 340 to 360 MPa, which was slightly lower than the design value ${ }^{[28]}$.

Table 1 Reinforcement details of the ground floor frame

\begin{tabular}{|c|c|c|c|c|c|}
\hline \multirow[t]{2}{*}{ Structural component } & \multirow{2}{*}{$\frac{\text { Label }}{\text { B1 }}$} & \multicolumn{4}{|c|}{ Longitudinal reinforcement (unit: mm) } \\
\hline & & Bottom: & 8@25 & Top: & 6@25 \\
\hline & B2 & Bottom: & 8@25 & Top: & 8@25 \\
\hline \multirow[t]{4}{*}{ Beam } & B3 & Bottom: & 6@25 & Top: & 6@25 \\
\hline & B4 & Bottom: & 6@25 & Top: & 4@25 \\
\hline & B5 & Bottom: & 5@25 & Top: & 4@25 \\
\hline & $\mathrm{C} 1$ & \multicolumn{4}{|c|}{ 12@20 } \\
\hline \multirow[t]{2}{*}{ Column } & $\mathrm{C} 2$ & \multicolumn{4}{|c|}{ 10@20 } \\
\hline & $\mathrm{C} 3$ & \multicolumn{4}{|c|}{ 8@20 } \\
\hline
\end{tabular}




\subsection{Masonry structure on the first through seventh floors}

The upper masonry structure was constructed of hollow concrete blocks. As shown in Figure 2, the masonry walls were laid out along the central axes of the frame beams on the ground floor, and an atrium was constructed at the center of the building. The masonry wall thickness was $190 \mathrm{~mm}$. The design compressive strengths of the concrete blocks and the cement mortars are summarized in Table 2. The on-site rebound hammer test and the laboratory compressive test of the drilled cores indicated that the design requirements of the actual strengths were met ${ }^{[24,29-31]}$. The tie columns and the bond beams were arranged on every floor to confine the masonry walls. Their sectional dimension was $190 \times 190 \mathrm{~mm}$, with four longitudinal reinforcing bars having diameters of $12 \mathrm{~mm}$.

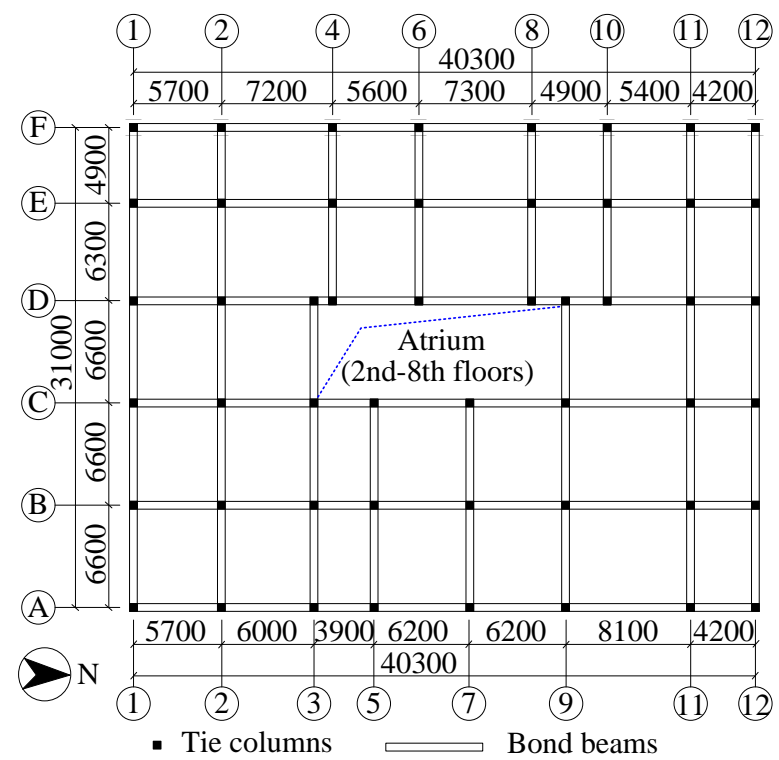

Figure 2 The arrangement of the bond beams and tie columns of the masonry on the first through seventh floors (unit: $\mathrm{mm}$ )

Table 2 Design compressive strength of concrete blocks and mortar

\begin{tabular}{ccc}
\hline \multirow{2}{*}{ Floor } & $\begin{array}{c}\text { Design compressive strength of concrete block } \\
(\mathrm{MPa})\end{array}$ & $\begin{array}{c}\text { Design compressive strength of mortar } \\
(\mathrm{MPa})\end{array}$ \\
\hline 1 & 20 & 10 \\
2 & 20 & 7.5 \\
3 & 10 & 7.5 \\
$4-6$ & 10 & 5 \\
7 & 10 & 2.5 \\
\hline
\end{tabular}




\section{Fire related data of the building}

The first-year occupation of the ground floor of the Hengzhou Building comprised an herbal medicine wholesale market. However, in 1999, it was banned under the market's consolidation. After that, its function underwent a number of changes, namely, to a warehouse, to a store for chemical materials, such as polyethylene film, nylon rope, linoleum, etc. (which are flammable materials with high levels of heat release). The building came under attack from a fire that struck on the morning (about 5:30 am) of November $3^{\text {rd }}$, 2003. The site observation of the building's debris, and the interview of the witnesses, indicated that the fire propagated quickly through a large portion of the ground floor, while the upper floors were not affected. The fire lasted for more than 3 hours, with continuous combustion, due to the large fire load. The building finally collapsed at 8:38 am.

An accurate time-history of the temperature distribution within the building was not recorded due to the lack of warning about the fire incident and the unavailability of a measurement tool. Such a tool had not been used in the small city for more than a decade. However, the fire related data was deduced from the site investigation and the laboratory test on the materials post-fire. The steel samples exposed to the fire were tested by the National Analysis Center for Iron and Steel (NACIS) of China using the metallographic analysis method ${ }^{[32]}$. The test report indicated that the reinforcing steels in some of the structural components were over-sintered but not melted. Given that the sintering and melting temperatures of reinforcing steels are $1250{ }^{\circ} \mathrm{C}$ and $1500{ }^{\circ} \mathrm{C}$, respectively, the highest temperature of steel was deduced to have between these two values. Further, based on the test data of the steel samples from different locations within the building, the temperature distribution on the ground floor of the building was determined, as shown in Figure 3. About 45.9\% of the bottom RC frame suffered a high temperature in excess of $800^{\circ} \mathrm{C}$ (the area was $573.46 \mathrm{~m}^{2}$ of the floor area $\left.1249.3 \mathrm{~m}^{2}(=45.9 \%)\right)$. Due to congestion by the surrounding buildings (Figure 4), it 
was very challenging for the firefighters to spray water directly onto the fire, especially from the west and north sides of the building. After approximately three hours of fire, the entire north-west region of the building collapsed. The collapsed zone of the building was, in general, consistent with the high-temperature zones. A range of photos of the collapsed building are given in Figure 5, with specific viewpoints shown in Figure 3.

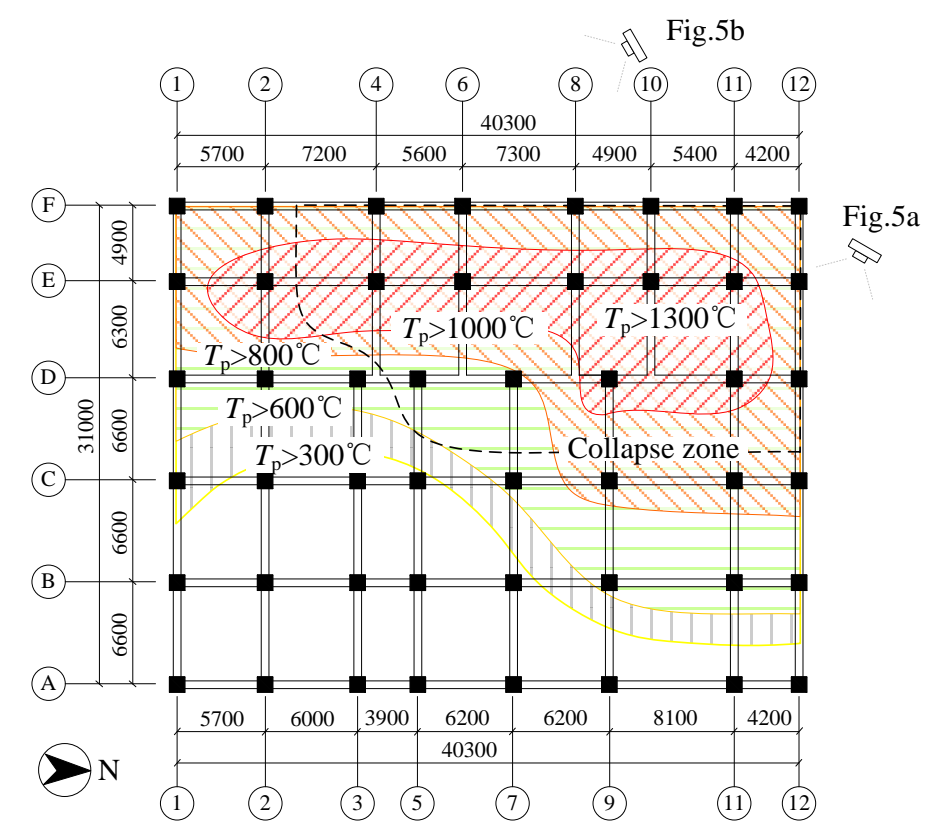

Figure 3 Temperature distribution and collapsed area

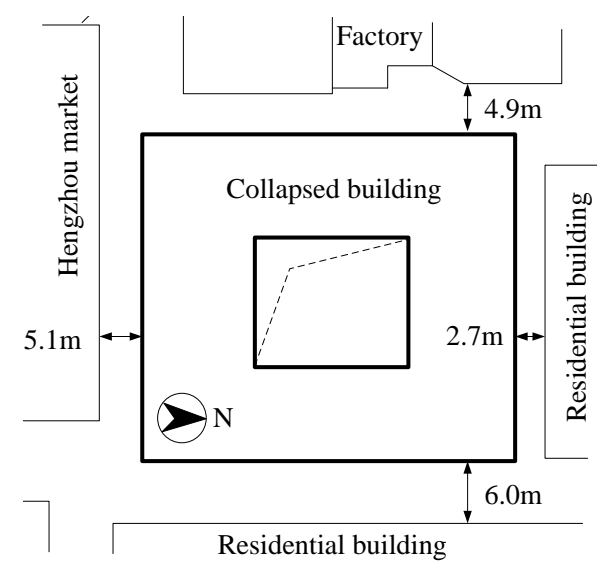

Figure 4 Geographic position of the Hengzhou Building 


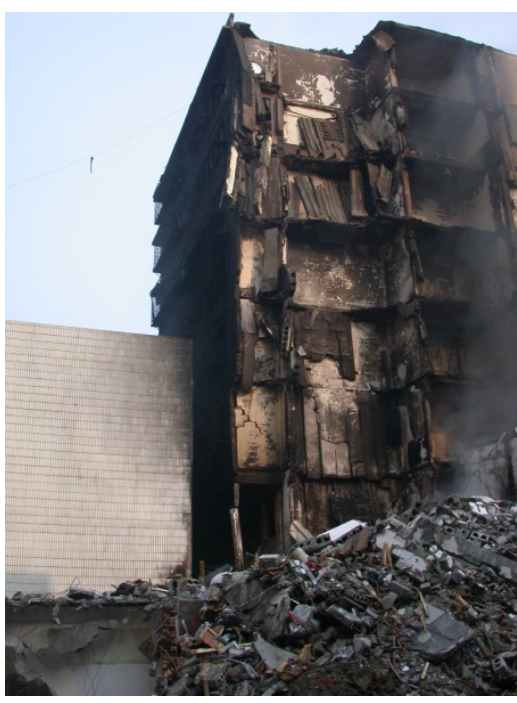

(a) The northeast side of the building

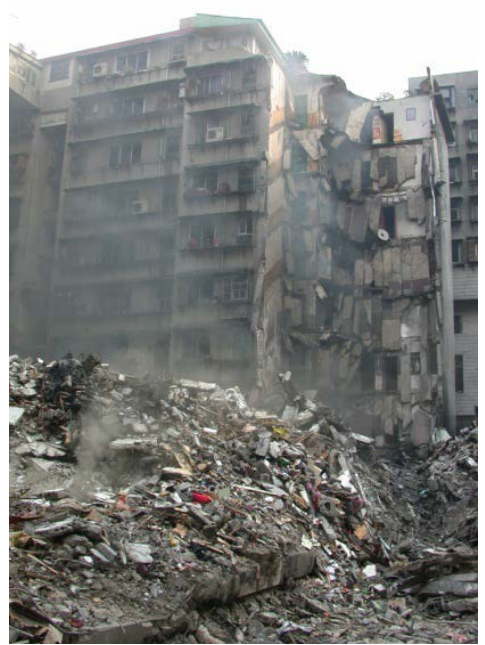

(b) The southeast side of the building

Figure 5 The collapse scene

Figure 6 shows the fire damage to the columns, whose locations are illustrated in Figure 2. The crushed concrete and brownish steel surface of Column D-9, located at the center of the fire, indicated that the cross-section of the concrete column suffered severe high-temperature damage. Column E-2, located on the border of the high temperature area, suffered spalling of the concrete, buckling of the longitudinal reinforcement, and compressive failure as clearly shown in Figure 6(b).

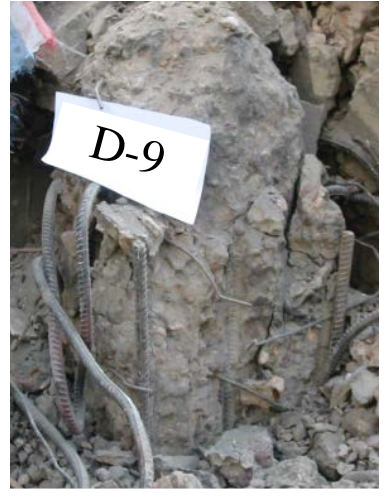

(a) Column D-9

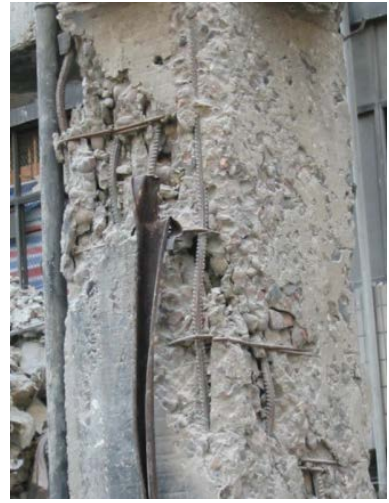

(b) Column E-2

Figure 6 Fire damage to the columns

Figure 7 shows severe damage to the beams located at the center of the fire. The concrete cover of Beam 8-E F (refer to Figure 2) fell off, causing the exposure of the stirrups and the longitudinal reinforcing steel. Subsequent to the collapse of Beam 
10-D E, the reinforcing steels were exposed, and some degree of spalling was observed. The metallographic analysis of the reinforcement indicated that the highest temperature of the steel was between $1250{ }^{\circ} \mathrm{C}$ and $1500{ }^{\circ} \mathrm{C}$, as described above.

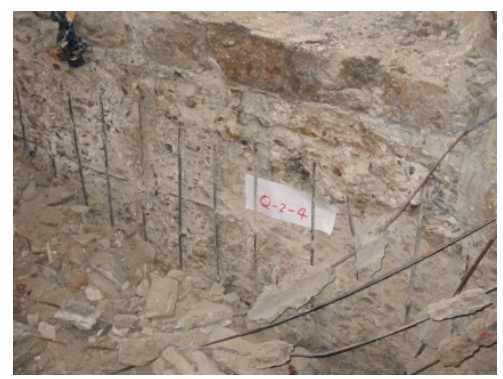

(a) Beam 8-E F

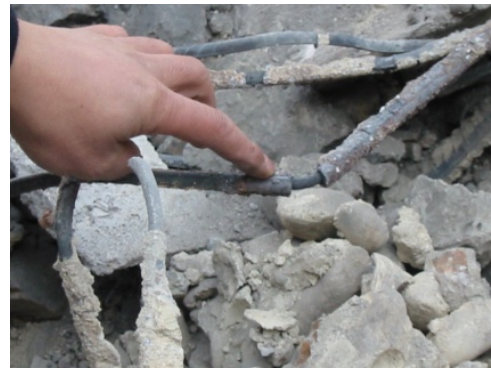

(b) Beam 10-D E

Figure 7 Fire damage to the beams

Based on the degree of damage to the columns and beams, the preliminarily site investigation concluded that damage of Columns E-8, E-10, E-11, D-9, and D-11 on the ground floor (refer to Figure 1) occurred due to very high temperature exposure, which is believed to have triggered the progressive collapse of the upper masonry structure. The columns were designed to resist a normal fire in accordance with the requirements of the design code ${ }^{[33]}$, regulated for commercial buildings. However the occupation of the ground floor of the building was changed to a warehouse filled with a large amount of flammable materials. Hence, the actual fire load developing at the time of the accident was extremely high, higher than originally considered acceptable in the design. The extraordinary fire load, covering a large area with a very high temperature, is considered to be the primary reason for the initial damage to the ground floor columns. In addition, the spalling of the concrete cover, and the construction error at the connections between the slabs and the RC frame, all accelerated the damaged to the columns.

\section{Numerical simulation}

To gain an in-depth understanding of the collapse mechanisms of the building under fire, a numerical simulation of the collapse process was performed using the finite element method. 


\subsection{Modeling details}

Given the complexity of the actual structure and the fire development process, the simplified structural model and the fire scenario was considered to perform an efficient analysis. The analysis was achieved by modeling the structure with fiber beam elements and shell elements, while the fire development was represented by a standard heating curve. The fracture of the structural components was simulated by the component failure criteria, which was associated with the element deactivation technique. Details of the numerical model are introduced in the following sub-sections.

\subsubsection{Numerical model for the ground floor RC frame}

The structure of the ground floor of the Hengzhou Building was in the form of a RC frame. A fiber beam element model, which takes into account the effect of high temperature, was developed to simulate the RC beams and columns on the ground floor. Existing research has demonstrated that this type of element model can simulate fire-induced mechanical behavior of RC elements with various cross sections ${ }^{[34]}$. Using this model, only six fiber beam elements along the longitudinal direction were required to represent a beam or a column, resulting in high computational efficiency. This outcome, in turn, facilitated an effective analysis of the entire structure ${ }^{[35]}$.

In the developed model, the cross-section of the beam or column was divided into a number of concrete and steel fibers that satisfied the plane-in-plane assumption. Different temperatures were assigned to different fibers to account for the non-uniform temperature distribution over the cross-section of the beams and columns. For each typical section of the beams and columns of the Hengzhou Building, which had different cross-sectional dimensions, and which were exposed to fire action with different maximum temperatures, the heat transfer analysis was conducted to calculate the time history of the temperature in each fiber of the section. The coupled thermo-mechanical constitutive laws of concrete and steel that account for the effect 
of high temperature ${ }^{[36,37]}$ were incorporated into the previously developed computer code ${ }^{[38]}$ for ordinary temperatures.

Given that the spalling mechanism is very complicated and associated with heat and moisture transfer, an accurate modeling of the concrete spalling was deemed to be very costly in computation costs, which would have further complicated the numerical simulation of the entire structural system. Therefore, the spalling of the concrete was not considered at this stage of the collapse simulation. Nevertheless, the effect of concrete spalling was evaluated separately and the relevant discussions are presented in Section 4.4.

The fiber beam element model developed in this study was validated via a series of tests on RC columns and beams under fire. Figure 8 presents one of the experimental verifications for a benchmark RC column test ${ }^{[39]}$. The thermal boundary condition in the heat transfer analysis used the conventional heat transfer coefficient, while the emissivity were set to $40 \mathrm{~W} /\left(\mathrm{m}^{2} \cdot \mathrm{K}\right)$ and 0.7 , respectively. A good agreement between the test and the analysis was obtained in term of the temperature field; however, some discrepancies were observed in the initial stage $(0-50 \mathrm{~min}$.) (Figure 8a). This is because the temperature field analysis employs the thermal parameters proposed by Lie ${ }^{[40]}$, in which the heat loss, via the moisture evaporation in concrete at $100{ }^{\circ} \mathrm{C}$, is converted into the additional equivalent thermal capacity of concrete, between $0^{\circ} \mathrm{C}$ and $100^{\circ} \mathrm{C}$. In doing so, the discontinuation of the thermal capacity of concrete, due to the moisture evaporation at $100^{\circ} \mathrm{C}$, is prevented which, in turn, facilitates the convergence of numerical computation. The process inevitably results in some errors in the calculation of the temperature field below $100{ }^{\circ} \mathrm{C}$, but the results are accurate at a higher temperature, as shown in Figure 8a. This explains the discrepancy of the temperature field, which also leads to an error in the mechanical response below 100 ${ }^{\circ} \mathrm{C}$ (Figure 8b); the outcome is not dissimilar to the findings of a number of existing studies ${ }^{[39][40]}$. On the other hand, the simulation at and beyond $50 \mathrm{~min}$. agrees well with the test results, and so is significant for a collapse simulation. 


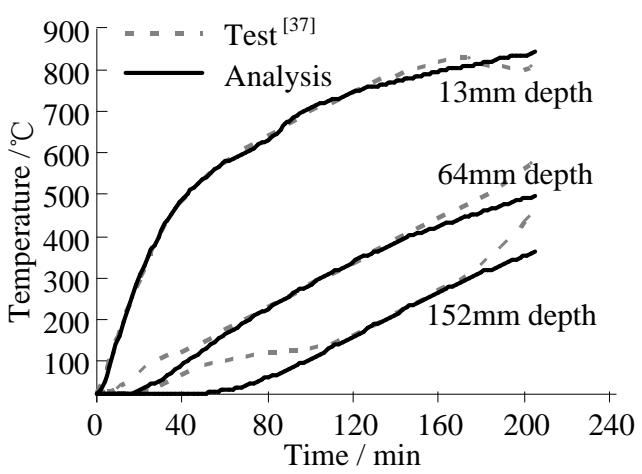

(a) Temperature field of the cross section

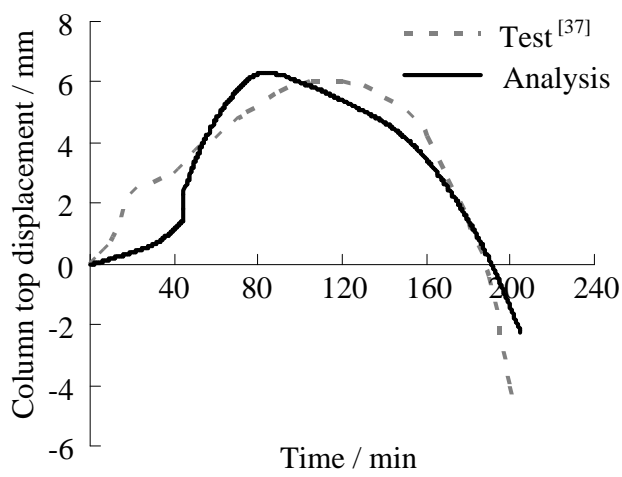

(b) Mechanical response of the structural component

Figure 8 Experimental verification of the fiber beam element model

\subsubsection{Numerical model for the unheated structural components}

The unheated RC beams on the ground floor, the bond beams, and the tie columns on the upper stories were simulated by an ordinary fiber beam element model ${ }^{[38]}$. The complex behavior of these RC members, such as the coupling of the axial and flexural internal forces, was accurately and effectively captured by this model. The shell elements were adopted to simulate the masonry walls composed of hollow concrete blocks in which the compressive crushing and the tensile fracture of the concrete were considered. The accuracy of these models was validated through experiments which were carried out at ambient temperature conditions ${ }^{[38]}$. The precast floor slabs were not firmly connected to the frame structure. In other words, the reinforcing steels in the slabs were not extended into the beams and, therefore, the slabs were detached from the cast-in-site beams. Such a structure violates the requirements of the concrete design code ${ }^{[26]}$. The slabs contributed only to the transfer of the gravity load, they had no effect on the fire resistance of the entire structural system. Therefore, in the numerical model, the floor slabs were not included; instead, the dead and live loads of the floor slabs were transformed into line loads acting on the walls or the framed beams.

\subsubsection{Element mesh}


The element mesh and connections are shown in Figure 9. Each RC beam/column on the ground floor was simulated by six fiber beam elements, considering the high temperature effect on the material behavior. Each bond RC beam/tie column on the upper stories was modeled by six normal fiber beam elements. Each masonry wall was represented by a $6 \times 6$ element mesh in which some elements were removed to simulate windows or doors.

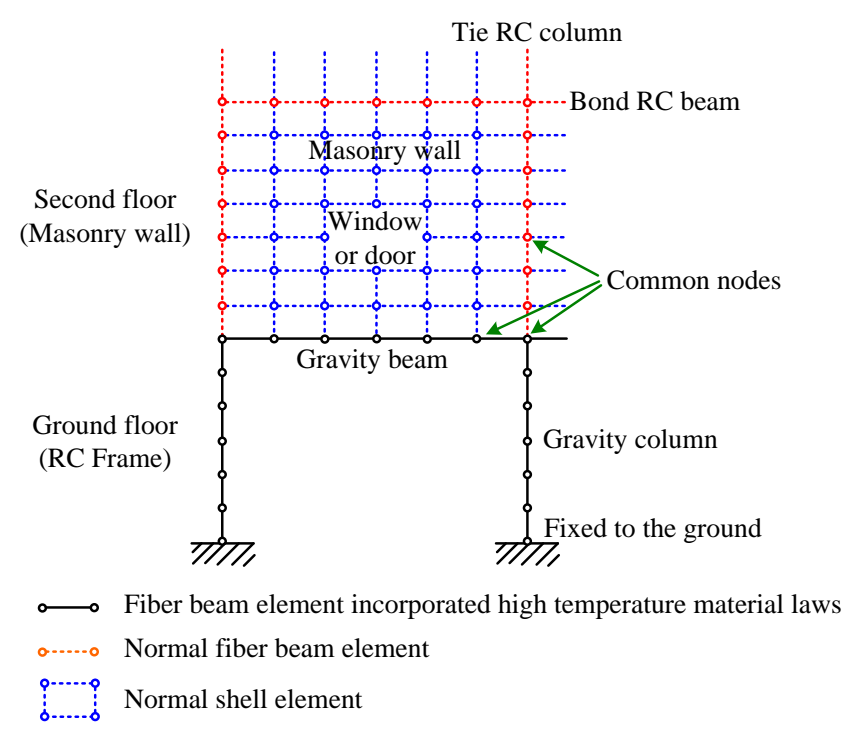

Figure 9 Modeling method of the Hengzhou Building

\subsubsection{Component failure criteria}

During the structural collapse, damage and fracture occurred in some members, causing a redistribution of the internal forces. By establishing the appropriate failure criteria for the structural components under high temperature, the fracture of these components was simulated by using the “elemental deactivation” technique ${ }^{[41]}$.

For the RC columns and beams exposed to fire, the tensile failure of the reinforcement occurred when its ultimate tensile strain was reached at a high temperature. Similarly, the compressive failure of concrete occurred when its ultimate crushing strain was reached. As defined in this work, the beam or column sectional failure was reached upon the fracturing of all the steel fibers or the crushing of all the concrete fibers within that section, respectively. The RC beams 
exhibited bending and tensile capacities under small and large deformations, respectively, which contributed to the collapse resistance of the building ${ }^{[42-44]}$. Similarly, bending and compressive mechanisms also existed in the columns under small and large deformations, respectively. The failure criteria allowed the RC beams and columns to undergo both small and large deformations, but they only failed with the large deformations. When a structural member reached its failure criterion, the corresponding element was subsequently removed from the finite element model using the "elemental deactivation” technique. As a result, the internal force of the removed element was also released ${ }^{[41]}$. The ultimate strains on the steel and concrete at high temperatures, suggested by Guo and Shi ${ }^{[37]}$, were adopted in the current work to determine the failure of the material fibers.

Simultaneously, the failure criteria for the unheated RC components followed the work of Lu et al. ${ }^{[38]}$. For the masonry walls, consisting of concrete blocks, failure was considered to have occurred when the crushing strain of the concrete or mortar was reached, and the corresponding element was subsequently deactivated.

\subsubsection{Simplification of fire development}

The fire dynamics of a real fire is highly complex. For this reason, an accurate time-history of temperature distribution in the current situation could not be recorded, as previously discussed. To facilitate the analysis, a simplified continuous heating process was assumed in which the traveling fire ${ }^{[45]}$ was not considered due to the observed rapid spread of fire on the ground floor. This was also based on the observation that the building collapsed during continuing violent combustion. In accordance with the type of burned products, the code specified hydrocarbon (HC) standard temperature-time curve ${ }^{[33]}$ was adopted; this is presented in Figure 10. The process was conceived for testing structural elements in a standard furnace exposed to hydrocarbon/chemical fires for the offshore and petrochemical industries. It is evident that the HC fire curve had a much quicker rise in temperature than that of ISO $834^{[46]}$, 
which was consistent with the burning characteristic of the petrochemical products. The maximum value of the HC standard temperature-time curves for different regions of the building was adjusted, based on the accident investigation report (see Figure 3). The heating time was set at $180 \mathrm{~min}$. as in the real situation. However, the duration of fire initiation to the building collapse may not have been accurately assessed due to the simplification of the fire development. Nevertheless, the collapse mechanism was truly represented, given that the real fire distribution was well considered.

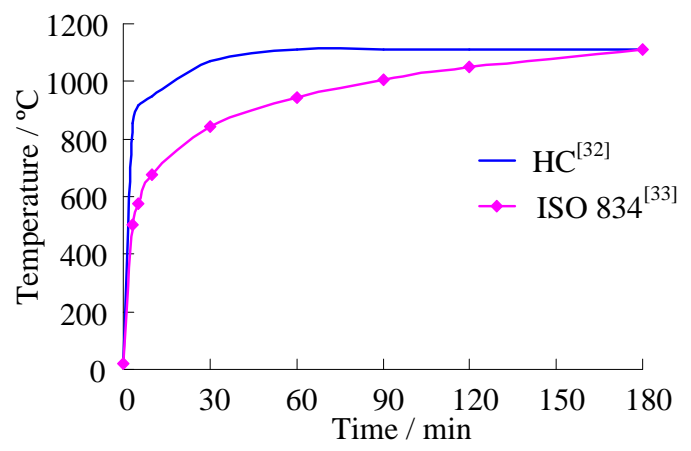

Figure 10 HC standard temperature-time curve

\subsection{Numerical simulation results}

In the numerical analysis, the time-varying temperature field of each component being heated in the fire accident was required to be calculated first. The material thermal parameters, the thermal radiation, and the convection parameters, as part of the temperature field analysis, were determined according to the Eurocode $2^{[47]}$. The material strengths were determined according to the laboratory test results. Subsequently the coupled thermo-mechanical analysis was performed; the gravity load was first applied to the unheated structure, and then superimposed with the fire load, i.e. the time-varying temperature field, until the collapse occurred.

The simulated collapse process of the structure is shown in Figure 11. As the fire developed, the bottom Columns, D9 and E4, located at the center of Zones A and B (see Figure 12), were damaged first. This damage resulted in a significant vertical displacement in the two zones and, subsequently, lead to damage in the upper 
masonry walls (Figures 11a and 11b). As the fire developed further, an initial collapse occurred in Zones A and B (Figure 11c), which altered the load transfer path of the entire structure and triggered the collapse of the adjacent areas, as shown in Figure 11d. A comparison of Figure 11d and Figure 3 demonstrates that the simulated collapse area agrees well with the actual one. Moreover, only damages in Zone A were observed from the site investigation, whereas damages in Zone B were identified from the numerical simulation. This outcome implies that numerical simulation is a powerful analysis tool for fire safety research. In the current numerical study, a total of 23,742 elements were used; this involved five hours computational time on a single CPU desktop. The proposed modeling method was highly efficient.

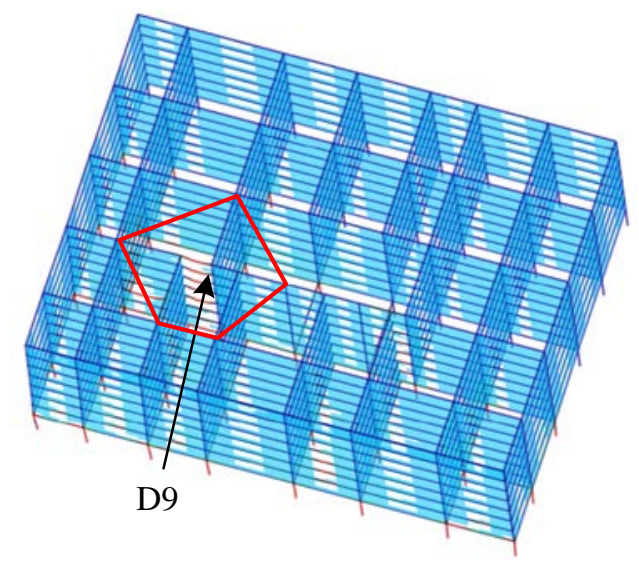

(a) Local damage in Zone A (88 min)

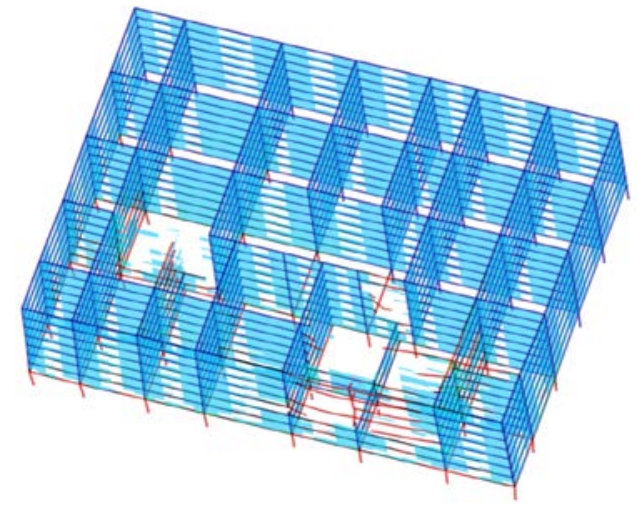

(c) Partial collapse in Zones A and B (109 min)

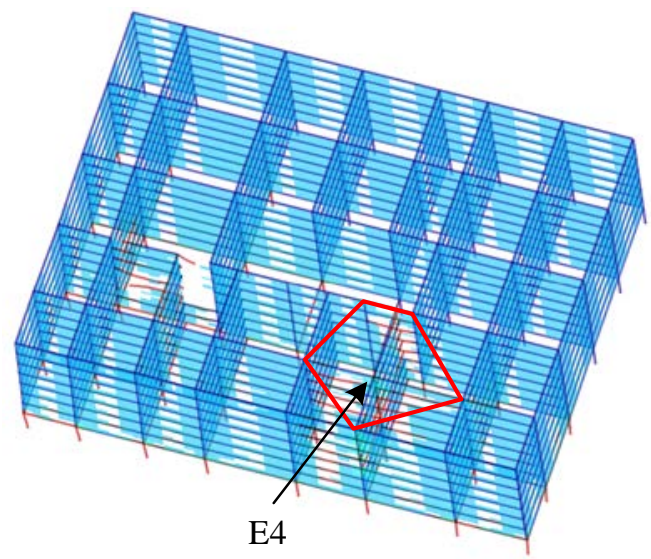

(b) Local damage in Zone B (89 min)

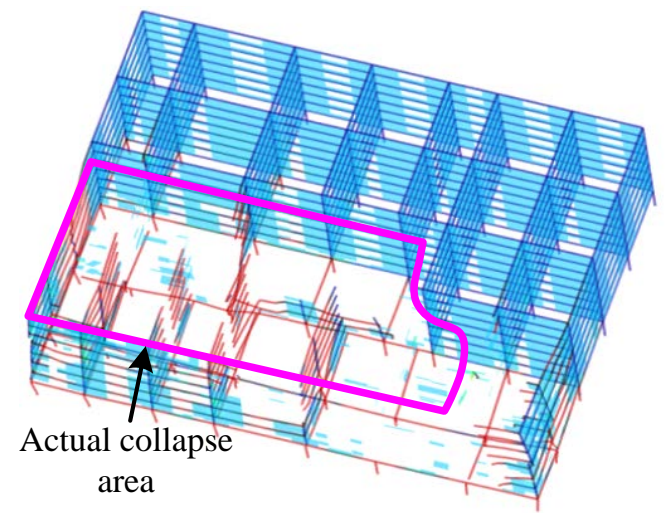

(d) Collapse in a wide range of areas (123 min)

Figure 11 Simulation of the fire-induced collapse process

The simulated collapse process revealed that the initial cause of the progressive collapse was the destruction of Columns D9 and E4, located at the center of Zones A 
and B (see Figure 12). The collapse occurred due to the following three factors. First, the fire temperature in these zones was significantly higher (greater than $800{ }^{\circ} \mathrm{C}$ ) than the other regions. As shown in Figure 3, Columns D9 and E4 reached a maximum temperature of $1300{ }^{\circ} \mathrm{C}$. Therefore, the fire damage to these two zones was more severe than in the remaining part of the structure. Two, the structural planar layout for Columns D9 and E4 carried a larger gravity load than did the other components (the shaded part of Figure 12), making them more vulnerable to fire. Third, the structural arrangements of Zones A and B were more complex than those of the other areas. The gravity load of the upper walls (4-E D and 10-E D), initially acting on the secondary beams, was transferred to the main girders (3 5-D and 9 11-D), and then to the columns. Thus, these structural elements appeared to exhibit more complicated internal force characteristics which were more vulnerable to damaged under the fire condition. Taking Beam 9 11-D and its parallel Beam 9 11-C in Zone A as an example, the vertical displacements and the mechanisms of these two beams, shown in Figure 13, had an identical longitudinal span (8.1m) and supported the slabs with similar widths $(12.9 \mathrm{~m}$ and $13.2 \mathrm{~m})$. This situation lead to near uniformly distributed gravity loads $q$ acting on the beams. However, an additional concentrated load $P$ transferred from the upper Wall 10-E D also acted on Beam 9 11-D. As a result, larger internal forces (i.e. shear force and bending moment) developed in Beam 9 11-D in comparison to Beam 9 11-C, and, in turn, induced a lager deformation, as shown in Figure 13. Moreover, the displacement of Beam 9 11-D reversed at about 88 min.; this was due to the load redistribution of the adjacent columns as a result of the high temperature actions (discussed in the following section). Given the abovementioned reasons, Zones A and B were the most vulnerable regions within the structure to initiate a collapse under fire. 


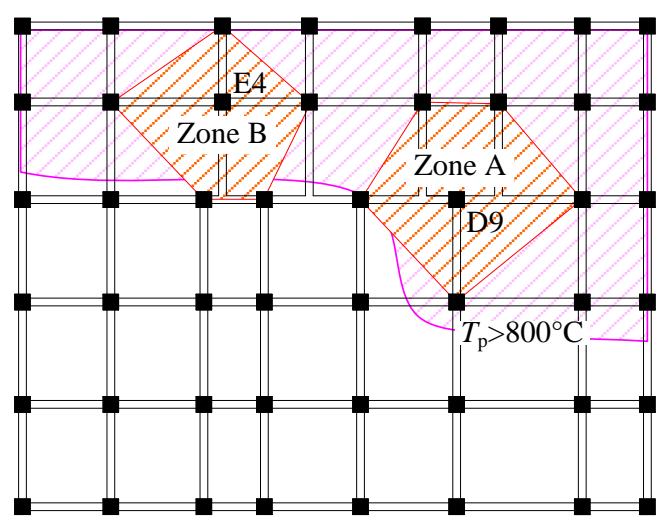

Figure 12 The load area borne by the initially damaged columns

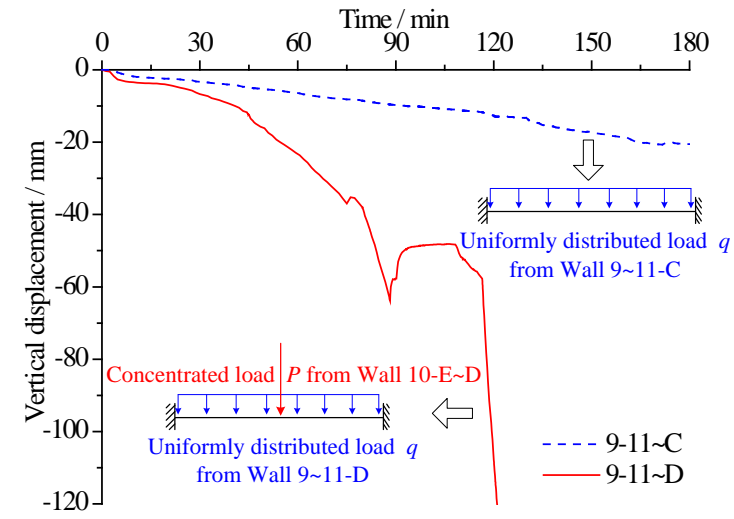

Figure 13 Vertical displacements of the frame beams

\subsection{Changes to the internal forces}

The axial forces of the columns in Zones $\mathrm{A}$ and $\mathrm{B}$, obtained by the numerical simulation, are shown in Figure 14. In the initial stage of fire (0-30 min.), the thermal expansion of the ground floor columns was restrained by the upper structure, leading to increased axial forces for all the columns affected by the fire. After $47 \mathrm{~min}$. more damage to Column D9, at the center of Zone A, reduced its internal axial force, which led to the redistribution of the internal forces. The axial forces then began to increase correspondingly in Columns E10 and D11. Reaching 88 min. of fire, the columns adjacent to Column D9 began to become damaged due to the redistributed incremental load and the fire-induced strength degradation, resulting in a rapid collapse in Zone A (Figure 11a). Subsequently, the axial forces in Columns D11, E8 and E10 decreased to zero. Column D7, located at the boundary of the collapsed areas, 
remained connected to the residual structure; thus its capacity was not completely lost. Column C9, which was outside of the collapsed zones, was not destroyed either, but its axial load decreased because the gravity load of the residual structure was reduced by the collapsed region.

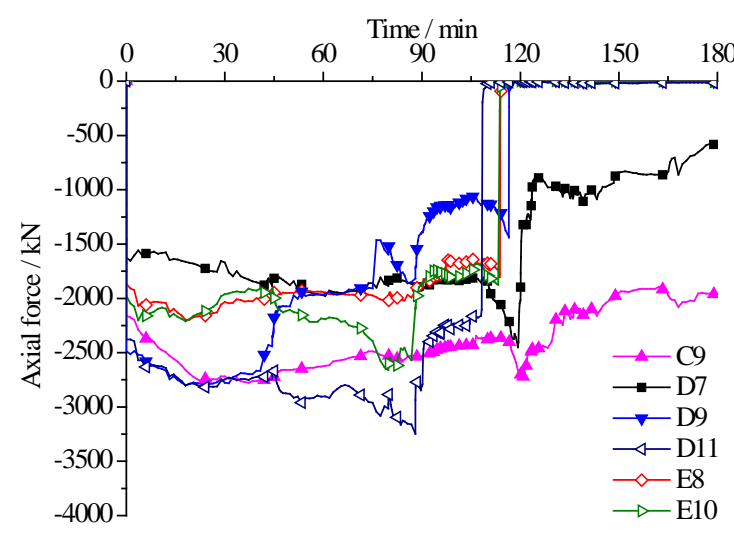

(a) Zone $\mathrm{A}$

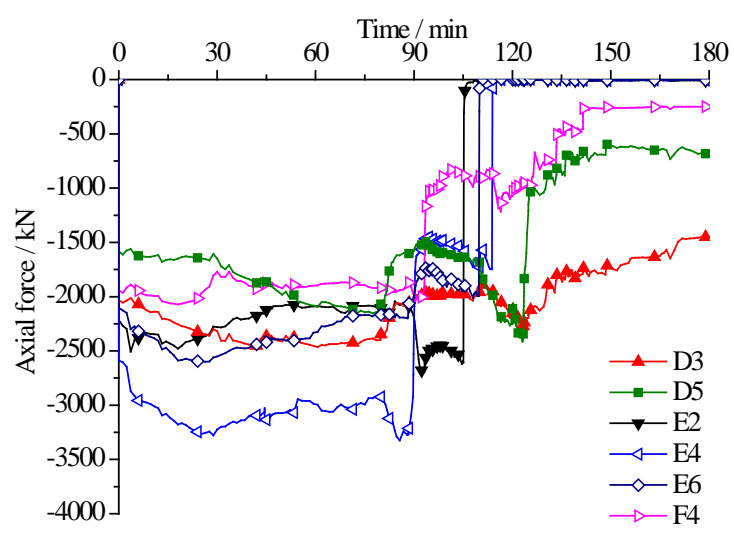

(b) Zone B

Figure 14 Axial forces of the frame columns

According to the above analysis, after Column D9 in Zone A was damaged, the gravity load, which was originally supported by Column D9, was redistributed to the surrounding columns, including D11, E8, and E10. At this stage, the structure was considered robust enough to resist fire because of the efficient alternative load path provided by D11, E8, and E10. However, the surrounding columns consequently failed due to the strength degradation induced by the continuing development of the fire and the increased gravity load. Such a failure resulted in an insufficient capacity of the alternative load path in the structural system; this, in turn, lead to the initial collapse of Zone A. Therefore, the primary reason for the structural collapse was the weakening of the resistance of the structure due to excessive fire load and very high temperature over a large area. Neither of these aspects are considered in the Chinese fire design $\operatorname{code}^{[33]}$. Further, the collapse mechanism of Zone B was similar to that of Zone A, as indicated by Figure 14b; however, it was not repeated here.

\subsection{Effect of concrete spalling}

To evaluate the effect of concrete spalling on the structural collapse, a separate 
simulation, taking into account the spalling phenomenon, was performed herein. For the reason given in Section 4.1.1, a simplified model of concrete spalling, proposed by Kodur et al. ${ }^{[48]}$, was incorporated in the fiber beam element. In this model, the concrete spalling occurred when the temperature of the concrete exceeded $350{ }^{\circ} \mathrm{C}$. Subsequently, the contribution of the spalled concrete to the strength and stiffness of the structural elements was not considered in the numerical model. The simulated collapse process, taking into account concrete spalling, was found to be almost identical to that where the spalling effect was not considered, as shown previously in Figure 11. However, a comparison of the time history curves of the axial forces of Columns D9 and E4 (Figure 15) revealed that the collapse time of the building was reduced from $88 \mathrm{~min}$ to $78 \mathrm{~min}$ when spalling was considered. This appears to have occurred as the spalling reduced the effective sectional area of Columns D9 and E4 which, in turn, accelerated their strength deterioration and shortened their failure time. In addition, the concrete spalling also resulted in a sudden loss of the axial forces in Columns D9 and E4 when the collapse occurred. The outcome seems to have resulted from the fact that the spalling reduced the compressive capacities of the columns under fire, thereby weakening the load redistribution capacity.

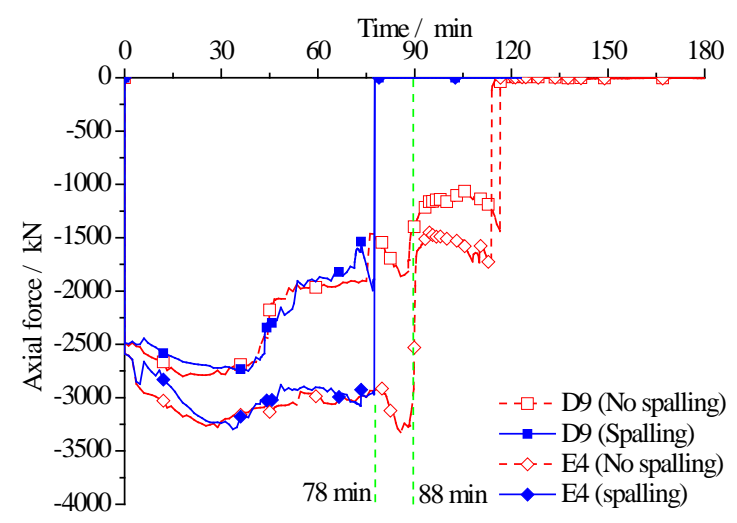

Figure 15 Effect of concrete spalling on the axial forces of the frame columns

Moreover, the simplified spalling model adopted in this study neglected the effect of thermal boundary condition, moisture transfer, vapor pressure, and concrete stress. Thus, it was unable to accurately account for the likely time and depth of the spalling. 
Hence, the above discussion on the spalling effect is case specific to this study. Accordingly, the findings cannot be generalized to other cases unless an advanced spalling model is developed which is suitable for global analyses of entire structural systems.

\section{Progressive collapse prevention design considerations against fire}

A number of progressive collapse prevention design considerations against fire are presented here. First, the key structural components in a system refer to those that bear a large gravity load while being vulnerable to fire. Such key components, as Columns D9 and E4 in the Hengzhou Building, greatly affect the collapse resistance of the RC frame in a fire. Subsequent to the failure of these components, their originally supported gravity load is then transferred to a large, unbalanced load acting on the residual structure, which also suffers fire-induced damages. The capacity of the residual structure to redistribute the internal forces is continuously weakened with the fire's development. These factors may cause an unbalanced load beyond the resistance of the residual structure, thereby triggering a progressive collapse.

The initial local failure of several structural members in a building structure, due to accidental events, such as fire, gas explosions, or vehicle impact, may propagate, from member to member, and eventually result in the collapse of a large portion of or the entire structural system, described as a progressive collapse ${ }^{[49]}$. In the conventional progressive collapse design $\operatorname{codes}^{[50,51]}$, the alternative load path method and the local resistance method are recommended to enhance the robustness of the building structures. For the alternative load path method, the initial local damage is allowed, but the consequent progressive collapse is prevented, by enhancing the remaining structures to bridge over the initial local damage. In contrast, the local resistance method is much simpler in which the bending and shear capacities of the regulated structural members is enhanced to satisfy some special requirements. However, the characteristic of fire-induced progressive collapse is not considered in these 
regulations. Based on the above discussion, when a building structure is exposed to an excessive fire covering a large area, the alternative load path for a key element may also be weakened. As a consequence, the alternative load path method may not be reliable for this situation. In addition, the local resistance method only requires enhancement of the capacity of the perimeter columns and load-bearing walls of the bottom two stories under normal temperature ${ }^{[51]}$. However, the fire resistance of the interior members, which are more vulnerable to fire-induced collapse prior to other structural members, was not considered in the present study. Therefore, an efficient method to prevent the progressive collapse of a building structure exposed to a fire is to determine the key components in the structural system and protect them from being damaged by increasing its high-strength redundancy, or installing fire protections.

Second, for buildings with high fire risks, the special design of the fire compartment is required to partition the large structural space into several smaller spaces to prevent the spread of the fire throughout a large part of the building. In accordance with the analysis of the Hengzhou Building, if the RC frame on the ground floor was exposed to a large, severe fire, progressive collapse, it is unlikely to be prevented following the initial local damage. An optimized fire compartment also helps to control the scope of the fire in a building and, in turn, reduces the fire damages to the overall structure.

However, the existing regulation about the fire compartment may not be effective in preventing the fire-induced progressive collapse of a building structure. The maximum area of the fire compartment zone varied from $500 \mathrm{~m}^{2}$ to $2500 \mathrm{~m}^{2}$, which is regulated in the existing code ${ }^{[33]}$, based on the function and safety level of the building. However, these dimension are not targeted for the prevention of fire-induced progressive collapse. For example, in the Hengzhou Building, the area of the ground floor exposed to fire exceeding $300{ }^{\circ} \mathrm{C}$ was approximately $839.44 \mathrm{~m}^{2}$, which was still less than $1000 \mathrm{~m}^{2}$ (i.e. the minimum requirement for warehouses). As shown in the current case study, a building will still collapse even it complies with the fire compartment requirement. Therefore, the fire compartment needs to be further 
investigated to consider fire-induced progressive collapse.

Third, the integration and connection of the structural members are important to the robustness of the structural system in a fire. In the Hengzhou Building, the precast slabs were not firmly tied into the RC frame, which violated the corresponding design code $^{[26]}$. If the slabs were integrated with the RC frame, the capacity and restraint of the columns would have been improved; in turn, this would have reduced the structural deformation and prevented or delayed the collapse of the critical columns on the ground floor. Consequently, improving the integration and connection of the structural members are actions that would mitigate the progressive collapse of building structures in fire.

\section{Conclusions}

In this paper, the fire-induced collapse of an 8-storey RC-frame-supported masonry building is reported and modeled. Information on the structure and the fire scenario has been presented. Using the proposed numerical modeling technique, the fire-induced collapse of the building was analyzed. The preliminary results indicate that the collapse of the building was likely due to the severe fire to which it was exposed (about $45.9 \%$ of the bottom storey of the RC frame was predicted to have experienced temperatures in excess of $800^{\circ} \mathrm{C}$, and its central area was predicted to have reached almost $1300^{\circ} \mathrm{C}$ ). Such a situation was thought to have significantly weakened its residual capacity and ability to redistribute the unbalanced gravity loads. Two vulnerable zones surrounding Columns D9 and E4 were severely damaged and may have triggered the progressive collapse of the entire building. The initial damage of these zones may have been due to very high temperature exposure, larger gravity loads, and a complex load transfer mechanism. The influence of concrete spalling on the collapse simulation is also discussed, although the discussion is specific to the particular case of this study where a simplified spalling model is used and, as such, should not be treated as a generalized conclusion. Nevertheless, the numerical 
analysis outcomes have provided practical design considerations on the key structural components, the fire compartments, and the structural robustness are given which should aid in the prevention of the fire-induced progressive collapse of RC frame structures.

\section{References}

[1] Building Research Establishment Ltd (2003) Client report: results and observations from full-scale fire test at BRE Cardington (Client report number 215-741). Cardington

[2] Sun R, Huang ZH, Burgess IW. (2012) Progressive collapse analysis of steel structures under fire conditions. Eng Struct. 34(2): 400-413

[3] Gillie M, Usmani AS, Rotter JM (2001) A structural analysis of the first Cardington test. J Constr Steel Res. 57(6): 581-601

[4] Gillie M, Usmani AS, Rotter JM (2002) A structural analysis of the Cardington British Steel Corner Test. J Constr Steel Res. 58(4): 427-442

[5] Lamont S, Usmani AS, Drysdale DD (2001) Heat transfer analysis of the composite slab in the Cardington frame fire tests. Fire Saf J. 36(8): 815-839

[6] Mostafaei H (2013) Hybrid fire testing for assessing performance of structures in fire-Application. Fire Saf J. 56(2): 30-38

[7] Robert F; Collignon C, Scalliet M (2013) Large scale fire test on tunnel segment: Real boundary conditions in order to evaluate spalling sensitivity and fire resistance. In: Proceedings of the 3rd International Workshop on Concrete Spalling due to Fire Exposure, Paris, France

[8] Drysdale D (2011) An introduction to fire dynamics. John Wiley \& Sons, Inc., New York.

[9] Franssen JM (2005) SAFIR: a thermal/structural program modelling structures under fire. Eng J, AISC. 42(3): 143-158

[10] Cai J, Burgess IW, Plank RJ (2003) A generalised steel/reinforced concrete beam-column element model for fire conditions. Eng Struct. 25(6): 817-833

[11] Gilliea M, Usmani A, Rotter M, O’Connor M (2001) Modelling of heated composite floor slabs with reference to the Cardington experiments. Fire Saf J. 36(8): 745-767 
[12] Sanad AM, Usmani A, Rotter JM, O’Connor M (2000) Composite beams in large buildings under fire: numerical modelling and structural behaviour. Fire Saf J. 35(3): 165-188

[13] Yin YZ, Wang YC (2004) A numerical study of large deflection behaviour of restrained steel beams at elevated temperatures. J Constr Steel Res. 60(7): 1029-1047

[14] Usmani AS, Chung YC, Torero JL (2003) How did the WTC towers collapse: a new theory. Fire Saf J. 38(6): 501-533

[15] Quintiere JG, di Marzo M, Becker R (2002) A suggested cause of the fire-induced collapse of the World Trade Towers. Fire Saf J. 37(7): 707-716

[16] National Institute of Standards and Technology (2005) Final report on the collapse of the world trade center towers. Gaithersburg

[17] McAllister T, Sadek F, Gross JL, Averill JD, Gann RG. (2013) Overview of the structural design of world trade center 1, 2, and 7 buildings. Fire Tech. 49(3): 587-613

[18] Kotsovinos P, Usmani A. (2013) The world trade center 9/11 disaster and progressive collapse of tall buildings. Fire Tech. 49(3): 741-765

[19] McAllister TP, Gross JL, Sadek F, Kirkpatrick S, MacNeill RA, Zarghamee M, Erbay OO, Sarawit AT (2013) Structural response of world trade center buildings 1, 2 and 7 to impact and fire damage. Fire Tech. 49(3): 709-739

[20] Capote JA, Alvear D, Lazaro M, Espina P, Fletcher I, Welch S, Torero JL (2006) Analysis of thermal fields generated by natural fires on the structural elements of Tall Buildings. In: Proceedings of the International Congress on Fire Safety in Tall Buildings, Santander, Spain

[21] Fletcher IA, Borg A, Hitchen N, Welch S (2006) Performance of concrete in fire: a review of the state of the art, with a case study of the Windsor tower fire. In: Proceedings of the 4th International Workshop in Structures in Fire, Aveiro, Portugal

[22] Flint G, Lamont S, Lane B, Sarrazin H, Lim L, Rini D, Roben C (2013) Recent lessons learned in structural fire engineering for composite steel structures. Fire Tech. 49(3): 767-792

[23] Lamont S, Lane B, Flint G, Usmani A (2006) Behavior of structures in fire and real design a case study. J Fire Prot Eng. 16(2): 5-35. 
[24] The Ministry of Construction of the People's Republic of China (2001) Technical specification for inspecting of concrete compressive strength by rebound method (JGJ/T 23-2001). Beijing

[25] The Ministry of Construction of the People's Republic of China (1988) Technical specification for testing concrete strength with drilled core (CECS 03:88). Beijing; 1988

[26] The Ministry of Construction of the People's Republic of China (1989) Code for design of concrete structures (GBJ 10-89). Beijing

[27] General Administration of Quality Supervision, Inspection and Quarantine of the People's Republic of China (1988) Hot rolled ribbed steel bar for the reinforcement of concrete (GB 1499-98). Beijing

[28] General Administration of Quality Supervision, Inspection and Quarantine of the People's Republic of China (1991) Hot rolled low carbon steel wire rods (GB/T 701-91). Beijing

[29] State Bureau of Building Materials Industry (2000) Precast concrete paving units (JC/T 446-2000). Beijing

[30] State Bureau of Building Materials Industry (1997). Normal concrete small hollow block (GB 8239-1997). Beijing

[31] The Ministry of Construction of the People's Republic of China (2000) Technical standard for site testing of engineering (GB/T 50315-2000). Beijing

[32] Vander Voort GF (2004) ASM handbook: volume 9: metallography and microstructures. ASM International, Novelty.

[33] The Ministry of Construction of the People's Republic of China (2006) Code of design on building fire protection and prevention (GB50016-2006). Beijing

[34] Xu Y, Wu B (2009) Fire resistance of reinforced concrete columns with L-, T-, and +-shaped cross-sections. Fire Saf J. 44(6): 869-80

[35] Huang ZH, Burgess IW, Plank RJ (2009) Three-dimensional analysis of reinforced concrete beam-column structures in fire. J Struct Eng, ASCE. 135(10): 1201-1212

[36] Shi XD, Tan TH, Tan KH (2002) Concrete constitutive relationships under different stress-temperature paths. J Struct Eng, ASCE. 128(12): 1511-1518

[37] Guo ZH, Shi XD (2003) Behaviour of reinforced concrete at elevated temperatureand its calculation. Tsinghua University Press. Beijing (in Chinese) 
[38] Lu X, Lu XZ, Guan H, Ye LP (2013) Collapse simulation of reinforced concrete high-rise building induced by extreme earthquakes. Earthq Eng Struct Dyn. 42(5): 705-723

[39] Lie TT, Irwin RJ (1993) Method to calculate the fire resistance of reinforced concrete columns with rectangular cross section. ACI Struct J. 90(1): 52-60

[40] Lie TT, Celikkol B (1991) Method to calculate the fire resistance of circular reinforced concrete columns. ACI Struct J. 88(1): 84-91

[41] MSC Software Corp (2005) MSC.Marc Volume A: Theory and User Information

[42] Li Y, Lu XZ, Guan H, Ye LP (2011) An improved tie force method for progressive collapse resistance design of reinforced concrete frame structures. Eng Struct. 33(10): 2931-2942

[43] Li Y, Lu XZ, Guan H, Ye LP (2014) An energy-based assessment on dynamic amplification factor for linear static analysis in progressive collapse design of ductile RC frame structures. Adv Struct Eng. 17(8): 1217-1225

[44] Li Y, Lu XZ, Guan H, Ye LP (2014) Progressive collapse resistance demand of RC frames under catenary mechanism. ACI Struct J. 111(5):1225-1234

[45] Law A, Stern-Gottfried J, Gillie M, Rein G (2011) The influence of travelling fires on a concrete frame. Eng Struct. 33(5): 1635-1642.

[46] International Standard Organization (1999) International standard ISO 834-1: fire resistance tests - elements of building construction - Part 1: general requirements. Geneva

[47] European Committee for Standardization (2004) Eurocode 2: design of concrete structures. Part 1-2: general rules structural fire design (EN 1992-1-2). Brussels

[48] Kodur VKR, Wang TC, Cheng FP (2004) Predicting the fire resistance behavior of high strength concrete columns. Cement Concrete Comp. 26(2): 141-153.

[49] American Society of Civil Engineers (2005) Minimum design loads for buildings and other structures (ASCE7-05). Reston

[50] United States General Services Administration (2003). Progressive collapse analysis and design guidelines for new federal office buildings and major modernization projects. Washington D.C.

[51] Department of Defense (2010). Unified facilities criteria (UFC): design of structures to resist progressive collapse. Washington D.C. 
List of Tables and Figures:

Table 1 Reinforcement details of the ground floor frame

Table 2 Design compressive strength of concrete blocks and mortar

Figure 1 Structural arrangement of the ground floor frame and member sizes (unit: mm)

Figure 2 The arrangement of the bond beams and tie columns of the masonry on the first through seventh floors (unit: mm)

Figure 3 Temperature distribution and collapsed area

Figure 4 Geographic position of the Hengzhou Building

Figure 5 The collapse scene

Figure 6 Fire damage to the columns

Figure 7 Fire damage to the beams

Figure 8 Experimental verification of the fiber beam element model

Figure 9 Modeling method of the Hengzhou Building

Figure 10 HC standard temperature-time curve

Figure 11 Simulation of the fire-induced collapse process

Figure 12 The load area borne by the initially damaged columns

Figure 13 Vertical displacements of the frame beams

Figure 14 Axial forces of the frame columns

Figure 15 Effect of concrete spalling on the axial forces of the frame columns 